\title{
Radiological staging in neuroblastoma: computed tomography or magnetic resonance imaging?
}

\author{
Fatma C. Sarioglu $\mathrm{u}^{1, A, B, C, D, E, F}$, Muhammet Salman ${ }^{1, A, B, D}$, Handan Guleryuz ${ }^{1 A, B, D, E}$, Erdener Ozer ${ }^{2 B, C}$, Emre Cecen ${ }^{3 B, D}$, \\ Dilek Ince ${ }^{4 B, D}$, Nur Olgun ${ }^{4 B, D}$ \\ 'Dokuz Eylul University School of Medicine, Department of Radiology, Division of Paediatric Radiology, lzmir, Turkey \\ ${ }^{2}$ Dokuz Eylul University School of Medicine, Department of Pathology, Izmir, Turkey \\ ${ }^{3}$ Department of Paediatric Oncology, Medical Park Hospital, Izmir, Turkey \\ ${ }^{4}$ Dokuz Eylul University School of Medicine, Department of Paediatric Oncology, Izmir, Turkey
}

\section{Abstract}

Purpose: To compare the effectiveness of computed tomography (CT) and magnetic resonance imaging (MRI) in the staging of neuroblastomas according to the International Neuroblastoma Risk Group Staging System (INRGSS).

Material and methods: In this single-centre retrospective study we identified a total of 20 patients under the age of 18 years, who were admitted to our hospital with neuroblastoma between January 2005 and May 2018, and who had both CT and MRI examination. The INRGSS stages of tumours were evaluated by CT scan and MRI. Then, stages of tumours were described according to the INRGSS for CT and MRI, separately. The Spearman rank correlation test was used for statistical analysis. The $p$-value $<0.05$ was considered as statistically significant.

Results: The median age was 11 months, and the age range was one month to nine years. In our results; both MRI and CT were significant in the determination of radiological staging of NBL, $p<0.001$ and $p=0.002$, respectively. MRI was superior to CT in radiological staging. MRI was also superior for the detection of intraspinal extension, involvement of multiple body compartments, metastatic disease, and bone marrow infiltration. CT was more useful to consider the relationship between tumours and vascular structures.

Conclusions: MRI and CT have high diagnostic accuracy rates in the staging of pre-treatment neuroblastomas. MRI is important in pre-treatment evaluation of neuroblastomas because of the higher detection of metastases as well as the lack of ionising radiation.

Key words: children, neuroblastoma, staging, computed tomography, magnetic resonance imaging.

\section{Introduction}

Neuroblastoma (NBL) is the most common solid, extracranial malignant tumour in children, accounting for $8 \%$ to $10 \%$ of all childhood cancers and up to $15 \%$ of all paediatric cancer fatalities [1-3]. It is derived from primitive neural crest cells that would normally form the sympathetic nervous system [4]. The most common site of NBL is the adrenal gland (48\%), paraspinal ganglia in the retroperito- neum (25\%), chest (16\%), neck (3\%), and pelvis (3\%) [5]. The clinical presentation of NBLs varies based on the extent of disease and primary tumour location.

Imaging plays an essential role in the optimal assessment of the location and local extension of the primary tumour, surgical planning, follow-up of residual tumour, and the detection of relapse. Also, metastatic disease is evaluated by multimodality imaging procedures. The treatment planning and outcomes of NBLs are dependent on both the

Correspondence address:

Dr. Fatma Ceren Sarioglu, Dokuz Eylul University School of Medicine, Department of Radiology, Division of Paediatric Radiology, Izmir, Turkey,

phone: +905059628801, e-mail: drcerenunal@gmail.com

Authors' contribution:

A Study design · B Data collection · C Statistical analysis · D Data interpretation · E Manuscript preparation · F Literature search · G Funds collection 
Table 1. INSS classifications [6]

\begin{tabular}{|l|l|}
\hline Stage & Definition \\
\hline 1 & $\begin{array}{l}\text { Localised tumour with complete gross excision; ipsilateral } \\
\text { lymph nodes negative for tumour unless attached to and } \\
\text { removed with the primary tumour }\end{array}$ \\
\hline 2 & $\begin{array}{l}\text { Localised tumour with incomplete gross excision, or localised } \\
\text { tumour with nonadherent ipsilateral lymph nodes positive for } \\
\text { tumour }\end{array}$ \\
\hline 3 & $\begin{array}{l}\text { Unresectable unilateral tumour infiltrating across the midline } \\
\text { with or without regional lymph nodes positive for tumour; } \\
\text { localised unilateral tumour with contralateral regional lymph } \\
\text { nodes positive for tumour; or midline tumour with bilateral } \\
\text { unresectable infiltration or bilateral lymph nodes positive } \\
\text { for tumour }\end{array}$ \\
\hline 4 & $\begin{array}{l}\text { Any primary tumour with distant metastatic dissemination } \\
\text { (except stage 4S) }\end{array}$ \\
\hline 45 & $\begin{array}{l}\text { Localised primary tumour with metastatic dissemination } \\
\text { limited to skin, liver, and/or bone marrow* in patients younger } \\
\text { than 12 months }\end{array}$ \\
\hline
\end{tabular}

*Bone marrow involvement must be less than $10 \%$ at biopsy, and bone marrow must be negative on MIBG studies.

Table 2. INRGSS classifications [7]

\begin{tabular}{|l|l|}
\hline Stage & Definition \\
\hline L1 & $\begin{array}{l}\text { Localised tumour not involving vital structures (as defined } \\
\text { by image-defined risk factors) and confined to one body } \\
\text { compartment }\end{array}$ \\
\hline L2 & $\begin{array}{l}\text { Local-regional tumour with one or more image-defined risk } \\
\text { factors }\end{array}$ \\
\hline M & Distant metastatic dissemination (except stage MS) \\
\hline MS & $\begin{array}{l}\text { Metastatic dissemination limited to skin, liver, and/or bone } \\
\text { marrow* in patients younger than 18 months }\end{array}$ \\
\hline
\end{tabular}

*Bone marrow involvement must be less than $10 \%$ at biopsy, and bone marrow must be negative on MIBG studies.

stage and the risk group of disease. The stage of tumour is determined according to the International Neuroblastoma Staging System (INSS), which is designed according to the postoperative findings as well as the radiological findings, lymph node involvement, and bone marrow involvement (Table 1) [6]. Because INSS is not suitable for the preoperative staging, in 2009, the International Neuroblastoma Risk Group (INRG) task force proposed a new staging system for NBL, is called with the INRG Staging System (INRGSS), based on their radiological findings (Table 2) [7]. The main radiological points, named "image-defined risk factors (IDRFs)", were developed for the INRGSS with the confirmation of surgical findings (Table 3) [7]. The IDRFs vary depending on the primary tumour location; nevertheless, encasement of large vessels, intraspinal extension, airway compression, contiguous organ infiltration, and involvement of the multibody compartment are the main criteria that should be evaluated by computed tomography (CT) or magnetic resonance imaging (MRI) for the sur- gical planning. Ultrasound and scintigraphic techniques were inadequate for determination of local extension. CT and MRI are more useful techniques to determine the factors that affect the surgical planning.

There have been several studies about the imaging techniques for primary, relapsed, or residual tumour imaging [8-10]. However, to our knowledge, there has been no report on the assessment of the effectiveness of preoperative CT scanning and MRI in the preoperative radiological staging of NBL. The aim of this study is to compare the effectiveness of CT scanning and MRI in the staging of NBLs according to the INRGSS.

\section{Material and methods}

\section{Study population}

The local institutional review board approved this retrospective study and waived informed consent. From January 2005 to March 2018, 76 paediatric patients of NBL were registered in the paediatric oncology department at our institution. Fifty were excluded because no preoperative or pretreatment CT scans $(n=20)$, no MRIs $(n=26)$, and no contrast-enhanced CT scans $(n=4)$ were available for review. An additional six patients were excluded because the quality of their images was not sufficient for the staging analysis. The study included 20 patients with NBL, who had both contrast-enhanced CT scan and MRI at diagnosis. The patient group consisted of children without any treatment before the initial CT scan and MRI. The maximum interval between the CT scan and MRI was 21 days. All of the patients had INSS stages determined based on a combination of postoperative, radiological, metaiodobenzylguanidine (MIBG) scintigraphy, histopathological, and laboratory findings.

\section{Imaging protocol}

Computed tomography examinations were performed using a multi-detector CT scanner (Brilliance 64 Philips; Philips Medical Systems $\odot$, Eindhoven, The Netherlands). The routine scanning parameters for abdomen were voltage $80-120 \mathrm{kVp}$, current $120 \mathrm{~mA}$, and slice thickness $2 \mathrm{~mm}$. The chest CT scanning parameters were voltage $80-100 \mathrm{kVp}$, current $120 \mathrm{~mA}$, and slice thickness $2 \mathrm{~mm}$. Non-ionic contrast material was used. The images were performed after the administration of $2 \mathrm{cc} / \mathrm{kg}$ of $350 \mathrm{mgI} / \mathrm{ml}$ iodised non-ionic venous contrast material by an automatic injector at a rate of $3 \mathrm{ml} / \mathrm{s}$. Axial slices, and coronal and sagittal reformatted images were obtained.

The images were acquired using a 1.5 T MRI system (Gyroscan Achieva, release 8.1; Philips Medical Systems). The abdominal MRI protocol included coronal and axial T1-weighted turbo spin-echo (TSE) images (TR, $5.9 \mathrm{~ms}$; TE, $2.3 \mathrm{~ms}$; NEX, 4; flip angle, 65; section thickness, $0.8 \mathrm{~mm}$; intersection spacing, $0.6 \mathrm{~mm}$; matrix size, $416 \times 416$, 
Table 3. IDRFs definitions [7]

\begin{tabular}{|c|c|}
\hline Anatomic region & Description \\
\hline $\begin{array}{l}\text { Multiple body } \\
\text { compartments }\end{array}$ & $\begin{array}{l}\text { Ipsilateral tumour extension within two body compartments (i.e. neck and } \\
\text { chest, chest and abdomen, or abdomen and pelvis) }\end{array}$ \\
\hline Neck & $\begin{array}{l}\text { Tumour encasing carotid artery, vertebral artery, and/or internal jugular vein } \\
\text { Tumour extending to skull base } \\
\text { Tumour compressing trachea }\end{array}$ \\
\hline Cervicothoracic junction & $\begin{array}{l}\text { Tumour encasing brachial plexus roots } \\
\text { Tumour encasing subclavian vessels, vertebral artery, and/or carotid artery } \\
\text { Tumour compressing trachea }\end{array}$ \\
\hline Thorax & $\begin{array}{l}\text { Tumour encasing aorta and/or major branches } \\
\text { Tumour compressing trachea and/or principal bronchi } \\
\text { Lower mediastinal tumour infiltrating costovertebral junction between T9 } \\
\text { and T12 vertebral levels }\end{array}$ \\
\hline Thoracoabdominal junction & Tumour encasing aorta and/or vena cava \\
\hline Abdomen and pelvis & $\begin{array}{l}\text { Tumour infiltrating porta hepatis and/or hepatoduodenal ligament } \\
\text { Tumour encasing branches of superior mesenteric artery at mesenteric root } \\
\text { Tumour encasing origin of celiac axis and/or origin of superior mesenteric artery } \\
\text { Tumour invading one or both renal pedicles } \\
\text { Tumour encasing aorta and/or vena cava } \\
\text { Tumour encasing iliac vessels } \\
\text { Pelvic tumour crossing sciatic notch } \\
\end{array}$ \\
\hline Intraspinal tumour extension & $\begin{array}{l}\text { Intraspinal tumour extension (whatever the location) provided that more than one-third of spinal canal in axial plane } \\
\text { is invaded, the perimedullary leptomeningeal spaces are not visible, or the spinal cord signal intensity is abnormal }\end{array}$ \\
\hline $\begin{array}{l}\text { Infiltration of adjacent } \\
\text { organs and structures }\end{array}$ & Pericardium, diaphragm, kidney, liver, duodenopancreatic block, and mesentery \\
\hline \multicolumn{2}{|c|}{$\begin{array}{l}\text { Conditions that should be recorded but are not considered IDRFs are multifocal primary tumours, pleural effusion with or without malignant cells, } \\
\text { and ascites with or without malignant cells. }\end{array}$} \\
\hline
\end{tabular}

field of view, $200 \times 200 \mathrm{~mm}$ ), and coronal T2-weighted TSE images (TR/TE, 3495/90; flip angle, $90^{\circ}$; ETL, 56; FOV, $50 \times 180 \mathrm{~cm}$; ST, $5 \mathrm{~mm}$ ). The chest MR imaging protocol included coronal and axial T1-weighted turbo spin-echo (TSE) images (TR, $5.9 \mathrm{~ms}$; TE, $2.3 \mathrm{~ms}$; NEX, 4; flip angle, $65^{\circ}$; section thickness, $0.8 \mathrm{~mm}$; intersection spacing, $0.6 \mathrm{~mm}$; matrix size, $416 \times 416$, field of view, $200 \times 200 \mathrm{~mm})$, coronal T2-weighted TSE images (TR/TE, 3495/90; flip angle, $90^{\circ}$; ETL, 56; FOV, 50×180 cm; ST, $5 \mathrm{~mm}$ ). Additional contrast-enhanced axial and coronal T1-weighted images were obtained immediately after the injection of $0.1 \mathrm{mmol} / \mathrm{kg}$ of contrast. In case of necessity, sedation was applied either orally or intravenously for both techniques.

Some of the patients who had initial CT scans $(n=13)$ and initial MRI $(n=10)$ were referred from other institutions to our hospital, acquired using a technique that differed from ours; such as slice thickness. All of the images were archived at our Picture Archiving and Communication System.

\section{Image analysis and stage interpretation}

The INRGSS stage of tumours was considered according to CT and MRI by using IDRFs, separately. The local ex- tension of disease was evaluated considering IDRFs. The encasement of vessels, intraspinal extension, airway compression, contiguous organ infiltration, or involvement of the multibody compartment was evaluated to determine the presence or absence of IDRFs. Encasement of a vessel means that the vessel is completely or more than $50 \%$ surrounded by the tumour. No visible lumen for the vein is also considered as encased. If a tumour surrounded the vessels less than $50 \%$ or a visible lumen was seen in the vein, an IDRF was not present. However, when the tumour was in contact with the renal pedicle, IDRF was present, because renal pedicle may be risky in surgery. Intraspinal extension refers to invasion of more than onethird of the spinal canal in the axial plane, the perimedullary leptomeningeal spaces are not visible, or the spinal cord signal intensity is abnormal. If spinal foramina and epidural fat are invaded by the tumour in less than onethird of spinal canal in the axial plane, the IDRF is not present. Airway compression is used when the short axis of airway is reduced due to tumour compression. Contiguous organ infiltration means that the margins between tumours and organ are absent or ill-defined. Infiltration of pericardium, diaphragm, duodenopancreatic block, and mesentery is also considered as a presence of IDRF. Involvement of multibody compartment refers to ipsilateral 
tumour extension within two body compartments (i.e. neck and chest, chest and abdomen, or abdomen and pelvis). Stage L1 tumours are localised tumours with the absence of IDRF. They do not involve the vital structures and are confined to one body compartment. Stage L2 tumours are local-regional tumours with the presence of one or more IDRFs. Stage $M$ tumours are metastatic tumours that are revealed by using imaging modalities. Stage MS tumours are metastatic tumours in children younger than 18 months, with dissemination to skin, liver, and bone marrow.

The predicted INRGSS stages that were determined according to the INSS stages of the patients were calculated (INSS $1 \rightarrow$ INRGSS L1; INSS 2, $3 \rightarrow$ INRGSS L2; INSS 4 $\rightarrow$ INRGSS M; and INSS 4S $\rightarrow$ INRGSS MS) similarly in the study of Cohn et al. [5]. The readers recorded the patients' INRGSS stage (stage L1, L2, M, or MS) for CT and MRI, separately. The correlation between predicted INRGSS stages and found INRGSS stages according to the both CT and MRI were determined.

All of the images were evaluated by two paediatric radiologists (F.C.S., M.S.) who had two- and three-years experience, respectively. The readers were unaware of the operation findings and patients' final INSS stages. All patient data were hidden during the image analysis. The readers evaluated the CT and MR images and recorded the number of IDRFs and INRGSS stages of the tumours. The interval between the evaluation of CT scan and MRI was three weeks for both readers. When metastatic sites were detected, they were also recorded. In cases of the disagreement between the two radiologists, the images were re-evaluated and the final decision was reached by consensus. Also, a third radiologist (H.G.) who had 20 years of experience re-analysed the imaging data, and the majority opinion was accepted.

\section{Statistical analysis}

Statistical analysis was performed using IBM SPSS ver. 22.0 (IBM Corp., Armonk, NY, USA). The correlation between predicted INRGSS stage and INRGSS stage according to the CT and MRI was determined with the Spearman-Rank correlation test. The degree of interobserver agreement was determined for each of the analysed tumours by using weighted-kappa statistics. Kappa values normally lie between 0 and 1, with 0 indicating agreement purely by chance and 1 indicating perfect agreement [11] Calculated kappa values were interpreted as follows; $<0.20$, poor agreement; $0.21-0.40$, fair agreement; 0.41 0.60 , moderate agreement; $0.61-0.80$, good agreement; and 0.81-1.00, very good agreement [12].

\section{Results}

There were 20 patients, eight male and 12 female, aged one month to nine years (mean \pm SD, $22.9 \pm 28$ months), in the study. The time range between preoperative CT and MRI was $0-21$ days (mean $\pm \mathrm{SD}, 5.85 \pm 6.3$ days). Tumours were located in the adrenal glands in 11 patients (55\%), in the paravertebral region in four patients $(20 \%)$, in the posterior mediastinum in three patients $(15 \%)$, in the parapharyngeal region in two patients (10\%). All of the patients had been staged according to the INSS. Eight patients underwent surgery, nine patients had MIBG scintigraphy performed. MIBG scintigraphy was not used for all patients because those under 12 months (9/20 patients), and especially under six months, were ineligible, and there was a problem concerning the provided modality (2/20 patients). According to the INSS, two patients were in stage 1 , two patients were in stage 2 , six patients were in stage 3 , seven patients were in stage 4 , and three patients were in stage 4 S. Five of 10 patients who had metastatic disease and did not undergo MIBG scintigraphy at initial diagnosis were staged based on a combination of scintigraphic, radiological, and laboratory results. The predicted tumour stages according to INRGSS were two patients in L1 stage, eight patients in L2 stage, seven patients in M stage, and three patients in MS stage.

The degree of interobserver agreement was very good in the evaluation of the INRGSS stage with CT $(\mathrm{k}=0.906)$ and MRI $(k=0.954)$. The distribution of tumour stages according to the INSS, the predicted tumour stages according to the INRGSS, and the detected tumour stages according to the INRGSS for both modalities are summarised in Table 4. There was a significant relationship between the predicted tumour stages and the determined tumour stages both on CT and MRI ( $p=0.002, p<0.001$, respectively) (Figure 1). There was a higher correlation between the predicted tumour stages and the determined tumour stages by using MRI than CT. The correlation coefficiency was very strong in MRI ( $\rho$ value $=0.815)$ and strong in CT ( $\rho$ value $=0.658$ ). There were 10 patients in the localised stage and 10 patients in the metastatic stage. Seven of 10 patients $(70 \%)$ in the localised stages were detected by CT accurately. MRI demonstrated similar results with CT in the detection of localised stages (70\%). On CT scanning, seven of 10 patients were in the metastatic stage. On the other hand, the number of metastatic diseases was detected in nine of 10 patients by MRI. When considering the incompatible stages between predicted stages and detected stages by CT and MRI, there were six mismatches by CT and four mismatches by MRI. In case 3, intraspinal extension was detected solely by MRI. The stage was L1 according to CT and L2 according to MRI. In case 6 , with INSS stage 1 , predicted stage was L1 and detected stage was L2 according to both modalities, and renal pedicle invasion was present; however, there was no residual tumour after surgery. In case 7 , liver metastases were not seen on CT, whereas they were detected on MRI (Figure 2). In case 8, bone metastasis was not detected by CT; however, it was revealed by MRI (Figure 3 ). In case 10, the stage was $\mathrm{M}$ due to the humerus metastasis 
Table 4. The distribution of tumour stages according to the INSS, the predicted tumour stages according to the INRGSS and the detected tumour stages according to the INRGSS

\begin{tabular}{|c|c|c|c|c|c|c|c|c|c|}
\hline Case no & $\begin{array}{l}\text { Tumour } \\
\text { location }\end{array}$ & $\begin{array}{l}\text { INSS } \\
\text { stage }\end{array}$ & $\begin{array}{l}\text { INRGSS } \\
\text { stage } \\
\text { (predicted) }\end{array}$ & $\begin{array}{l}\text { INRGSS } \\
\text { stage } \\
\text { with CT }\end{array}$ & $\begin{array}{l}\text { INRGSS } \\
\text { stage with } \\
\text { MRI }\end{array}$ & $\begin{array}{c}\text { Number of } \\
\text { IDRFs } \\
\text { with CT }\end{array}$ & $\begin{array}{c}\text { Number of } \\
\text { IDRFs } \\
\text { with MRI }\end{array}$ & $\begin{array}{c}\text { Metastasis } \\
\text { by CT }\end{array}$ & $\begin{array}{c}\text { Metastasis } \\
\text { by MRI }\end{array}$ \\
\hline 1 & Adrenal & 4 & M & M & M & 1 & 1 & Bone & Bone (multiple) \\
\hline 2 & Retropharyngeal & 2 & L2 & L2 & L2 & 3 & 3 & - & - \\
\hline 3 & Paravertebral & 2 & L2 & L1 & L2 & 0 & 1 & - & - \\
\hline 4 & Adrenal & 4 & M & M & M & 5 & 5 & Bone & Bone \\
\hline 5 & Adrenal & 45 & MS & MS & MS & 0 & 0 & Liver & Liver \\
\hline 6 & Adrenal & 1 & $\mathrm{~L} 1$ & $\mathrm{~L} 2$ & $\mathrm{~L} 2$ & 0 & 0 & - & - \\
\hline 7 & Paravertebral & 45 & MS & L2 & MS & 5 & 4 & ND & Liver \\
\hline 8 & Adrenal & 4 & $M$ & $\mathrm{~L} 2$ & $M$ & 3 & 2 & ND & Bone \\
\hline 9 & Adrenal & 1 & L1 & L1 & L1 & 0 & 0 & - & - \\
\hline 10 & Adrenal & 4 & M & L1 & L1 & 0 & 0 & ND & ND \\
\hline 11 & Adrenal & 4 & M & M & M & 4 & 2 & Bone & Bone (multiple) \\
\hline 12 & $\begin{array}{c}\text { Posterior } \\
\text { mediastinal }\end{array}$ & 3 & $\mathrm{~L} 2$ & $\mathrm{~L} 2$ & L1 & 1 & 0 & - & - \\
\hline 13 & Paravertebral & 3 & L2 & L2 & L2 & 7 & 5 & - & - \\
\hline 14 & Adrenal & 3 & $\mathrm{~L} 2$ & $\mathrm{~L} 2$ & $\mathrm{~L} 2$ & 6 & 6 & - & - \\
\hline 15 & Adrenal & 4 & M & M & M & 5 & 3 & $\begin{array}{c}\text { Liver } \\
\text { and bone }\end{array}$ & $\begin{array}{c}\text { Liver } \\
\text { and bone }\end{array}$ \\
\hline 16 & Paravertebral & 3 & L2 & L2 & L2 & 2 & 2 & - & \\
\hline 17 & Adrenal & 4 & M & M & M & 4 & 4 & Bone & Bone \\
\hline 18 & $\begin{array}{c}\text { Posterior } \\
\text { mediastinal }\end{array}$ & 3 & L2 & L1 & L1 & 0 & 0 & - & - \\
\hline 19 & Paravertebral & 3 & L2 & L2 & L2 & 2 & 2 & - & - \\
\hline 20 & Parapharyngeal & $4 S$ & MS & MS & MS & 2 & 2 & Liver & Liver \\
\hline
\end{tabular}

INSS - International Neuroblastoma Staging System, INRGSS - International Neuroblastoma Risk Group Staging System, CT - Computed Tomography, MRI - Magnetic Resonance Imaging, ND - Not detected.
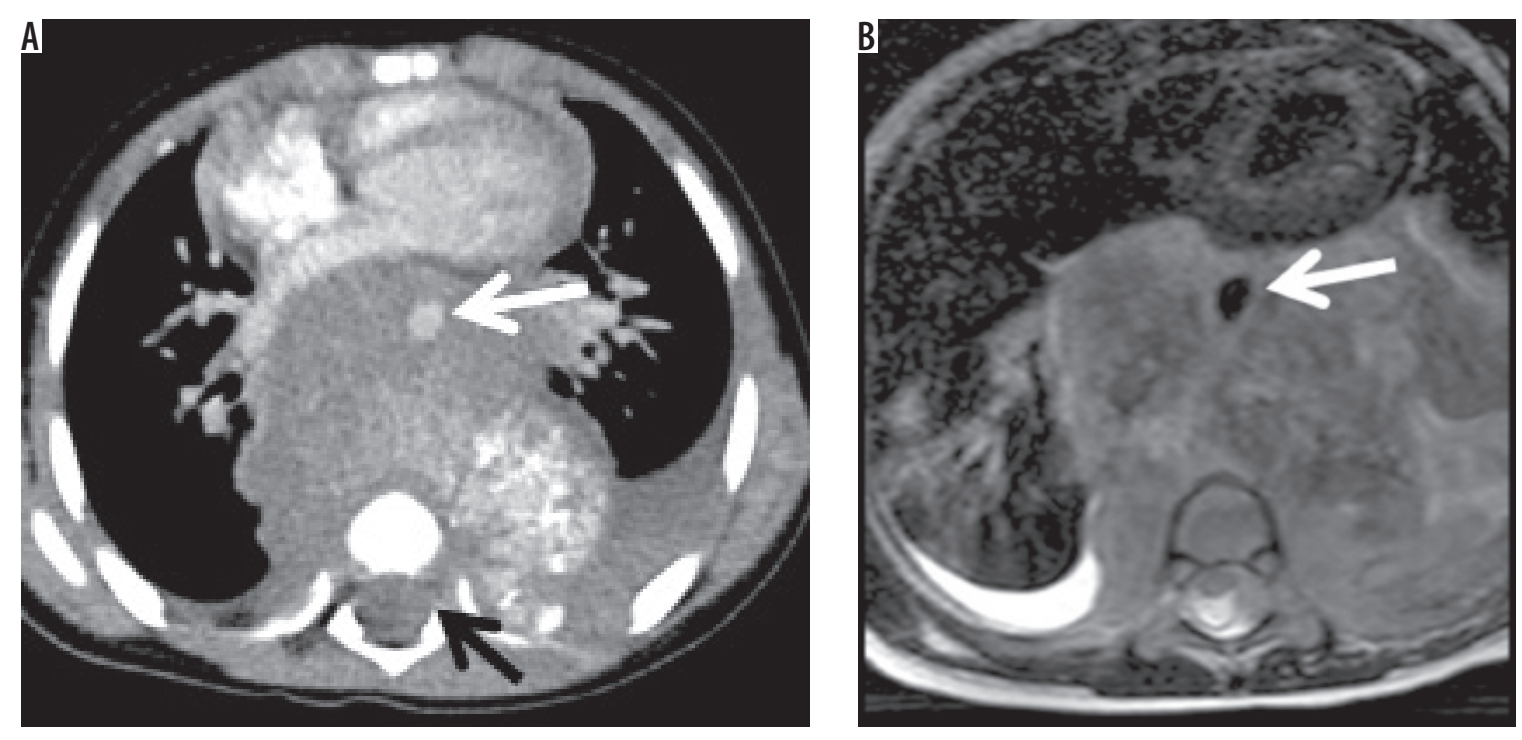

Figure 1. A 2-year-old male with neuroblastoma. Contrast-enhanced axial CT scan (A) and T2-weighted axial image on MRI (B) showed the posterior mediastinal mass. Aortic encasement (white arrow) and intraspinal extension were seen (black arrow) 

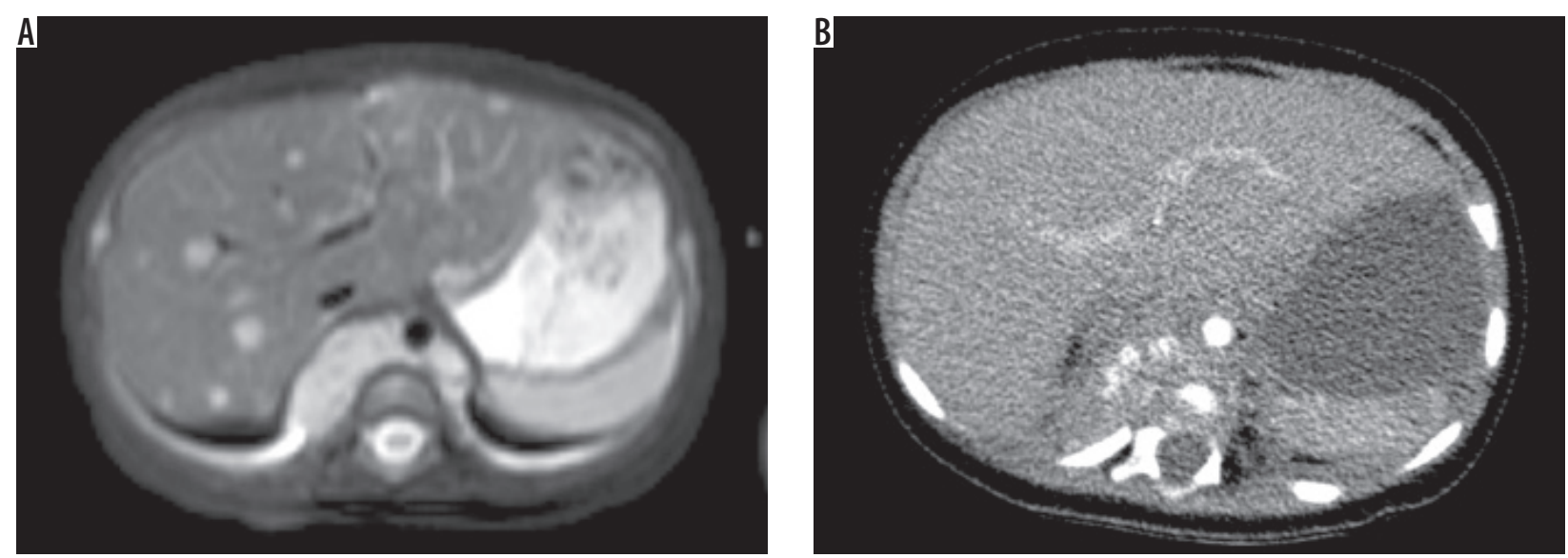

Figure 2. A 4-month-old girl with paravertebral neuroblastoma. A) T2-weighted axial image showed that multiple metastatic lesions in liver. B) 0n contrast-enhanced axial CT scan, they were not demonstrated
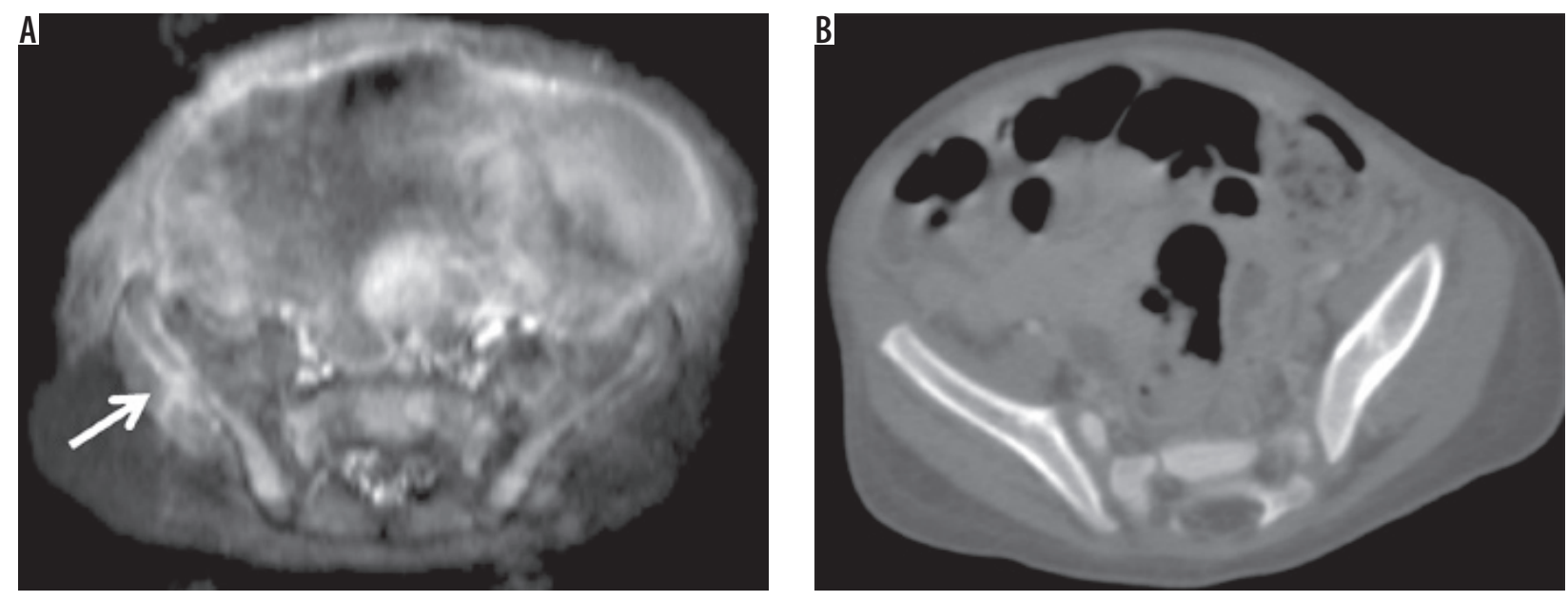

Figure 3. A 1-month-old girl with neuroblastoma in the adrenal gland. A) Contrast-enhanced T1-weighted axial image showed metastatic lesion in the right iliac wing (arrow). B) The metastatic iliac bone lesion could not be seen on contrast-enhanced axial CT scan

Table 5. The distribution of IDRFs with CT and MRIIDRFs with CT and MRI

\begin{tabular}{|l|c|c|c|c|c|c|} 
& $\begin{array}{c}\text { Vascular } \\
\text { encasement }\end{array}$ & $\begin{array}{c}\text { Intraspinal } \\
\text { extension }\end{array}$ & $\begin{array}{c}\text { Airway } \\
\text { compression }\end{array}$ & $\begin{array}{c}\text { Contiguous } \\
\text { organ infiltration }\end{array}$ & $\begin{array}{c}\text { Involvement of the multiple } \\
\text { body compartment }\end{array}$ & $\begin{array}{c}\text { Total number } \\
\text { of IDRFs }\end{array}$ \\
\hline CT & 38 & 2 & 2 & 13 & 4 & 59 \\
\hline MRI & 33 & 4 & 2 & 13 & 5 & 57 \\
\hline
\end{tabular}

IDRF - Image-defined risk factors, CT - Computed Tomography; MRI: Magnetic Resonance Imaging.

that was revealed in MIBG scintigraphy. However, CT or MRI was not available for the humerus. In case 12, posterior mediastinal NBL with subclavian vascular encasement was detected by CT. The stage was L 2 in CT and L1 in MRI. Case 18, whose expected INRGSS stage was L2, had posterior mediastinal mass between T2-T6 vertebral bodies. The detected stage was L1 for both modalities. There was no intraspinal extension, airway involvement, or vascular encasement.

The number of detected IDRFs was 59 and 57 using CT and MRI, respectively. There was a significant correlation between the determination of IDRFs by CT and MRI $(p<0.001, \rho$ value $=0.938)$ The detected IDRFs according to the both CT and MRI are summarised in Table 5. Vascular encasement was more detectable in CT; however, MRI was more useful in the determination of intraspinal extension and multiple body compartments. The results of CT and MRI in detecting airway involvement were similar. Furthermore, MRI detected a greater number of bone metastasis.

\section{Discussion}

Our results suggest that MRI was better than CT in determining the staging of the NBL according to INRGSS. MRI detected a greater number of intraspinal extensions, 
involvement of multiple body compartments, and bone metastases. Moreover, MRI showed the liver metastasis, which was not demonstrated by CT. CT was more useful in detecting vascular encasement.

The current staging procedures of NBL consist of CT or MRI for extension of tumour, bone scintigraphy or MIBG scintigraphy for skeletal metastases, and bone marrow aspiration and biopsy for marrow disease $[3,13,14]$. MIBG scintigraphy is not available for all patients due to some disadvantages, such as renal insufficiency. Although CT and MRI have long been used for imaging NBL, there has been no consensus about using CT or MRI in preoperative and surveillance imaging of NBL $[15,16]$. The choice of imaging modalities generally depends on clinicians' and radiologists' preference as well as the institutional availability [15]. CT is a rapid imaging method; by extension it enables sufficient data without anaesthesia [16]. Additionally, it shows the calcification in tumours. However, CT has ionising radiation, and children have a higher inherent sensitivity than adults to the negative effects of ionising radiation [16]. Compared with CT, MRI offers the advantages of higher contrast resolution, multiplanar acquisitions, and the lack of ionising radiation. In addition, an intravenous iodine-based contrast agent is required to provide soft tissue contrast with CT, whereas soft tissue contrast can be obtained without contrast material with MRI $[14,17]$. However, it requires anaesthesia because of the long acquisition time in the paediatric age group.

There have been a few reports concerning surveillance imaging for NBL $[10,16,18]$. MRI and a combination of MRI and MIBG scintigraphy are the preferred methods for surveillance imaging $[16,18]$. In a prospective cohort study by Siegel et al. [19], the accuracies of staging of CT, MRI, and bone scintigraphy were compared in patients with NBL. They found that CT and MR had statistically similar but had poor performance for local tumour staging. However, they assessed the images according to the INSS, not the evaluated IDRFs. In our study, the correlation between predicted stages and detected stages was higher in MRI than in CT (MRI $\rho$ value $=0.815$ and $p<0.001$; CT $\rho$ value $=0.658$ and $p=0.002$ ).

Imaging is essential to define the resectability of the primary tumour and to ascertain the presence or absence of metastatic disease. The INSS takes into account postoperative findings in staging, whereas INRGSS stratifies patients before surgical intervention based on IDRFs [7]. IDRFs play an important role in determining a treatment approach. It is crucial for the surgeon to know the extent of the tumour in detail before the operation. Although IDRFs are not required for staging patients with metastatic disease, the IDRF status of the primary tumour should be evaluated in all patients, including patients with metastatic disease, so that the impact of IDRFs on outcome as well as the surgical resection can be prospectively evaluated in all patients [7]. IDRFs should be evaluated by CT or MRI with multiplanar techniques. Results of a me- ta-analysis showed that CT is superior to the evaluation of vascular involvement [20]. MRI is more accurate than CT for the analysis of spinal canal extension $[3,21]$. In our study, there was a significant correlation in detecting of IDRFs between CT and MRI ( $\rho$ value $=0.938$ and $p<0.001)$. The vascular encasement was more detectable in CT. On the other hand, intraspinal extension was more discernible in MRI. The findings were compatible with the literature. The choice of the imaging technique can be made according to the primary tumour location. For example, CT may be preferred for the surrenal NBL to evaluate the vascular encasement. NBLs in the paravertebral region can be considered by MRI to assess the intraspinal extension [22].

Bone metastases and bone marrow infiltration are common involvement areas in NBLs. Although MIBG scintigraphy is the gold standard method to detect bone marrow involvement or metastatic bone disease, CT and MRI are also utilised in the evaluation of bones $[3,23]$. In particular, MRI is the most sensitive technique in determining bone metastasis due to its ability to show signal changes in fatty bone marrow [24]. CT is also useful in demonstrating bone metastasis, especially in the presence of pathological fracture or height loss. The presence of a single or multiple metastases in bones does not change the M-stage of the disease. However, it is essential to know the exact location of bone metastases in treatment planning and follow-up of the disease. It has been suggested that MRI is superior to CT in the evaluation of distant spread to bone or bone marrow [19]. In our study, CT was insufficient to detect bone metastasis in one of seven patients (case 8) whose bone metastasis was confirmed with MIBG scintigraphy. In two patients (case 1 and 11), CT was able to detect fewer bone metastases.

The other metastatic area of NBL is the liver. NBL is the most common cause of metastatic liver disease in the paediatric age group [25]. Four of 20 patients had liver metastases in our study. All of the liver metastases were detected by both techniques except in one patient (case 7), who had early portal venous phase image. These metastases could not be demonstrated in CT, which may be related to the phase of the contrast agent.

Although imaging at the initial stage of NBL is very important, surgical outcomes influence the staging. Even if IDRFs are negative, tumour resection may vary according to intraoperative conditions. It means that not all L1 stage disease can always be resected completely, and L2 stage may sometimes be resected completely. In our study, two patients, case 6 and case 18, were in predicted INRGSS stage L1 and L2, however, their detected stages for both modalities were L2 and L1, respectively.

Our study had several limitations. The retrospective study design was a major limitation of the present study. There were no available standard CT and MRI protocols because some CT scans and MRIs were performed at other institutions. Nonetheless, all of the images were evalu- 
ated by two paediatric radiologists and compatibility was very good. Our patient population was small. Although we had a great patient population with NBL, there was a small group who had both CT and MRI pretreatment due to starting treatment immediately after diagnosis. Also, MIBG scintigraphy was not available for all patients, so some of the patients' INSS stages were considered according to the clinical and imaging findings.

\section{Conclusions}

Although there is no consensus about the optimal imaging modality for assessment of pretreatment staging of
NBL, MRI is superior to CT in determining the stage of NBL in our study. MRI demonstrates a greater number of intraspinal extensions, involvement of multiple body compartments, and bone metastases. CT is more useful in detecting vascular encasement. CT and MRI have some advantages and disadvantages. Further studies are required to answer which modality should be preferred for the staging of NBL.

\section{Conflict of interest}

The authors report no conflict of interest.

\section{References}

1. Berthold F, Spix C, Kaatsch P, et al. Incidence, survival, and treatment of localized and metastatic neuroblastoma in Germany 19792015. Paediatr Drugs 2017; 19: 577-593.

2. Lonergan GJ, Schwab CM, Suarez ES, et al. Neuroblastoma, ganglioneuroblastoma and ganglioneuroma: radiologic-pathologic correlation. Radiographics 2002; 22: 911-934.

3. Swift CC, Eklund MJ, Kraveka JM, et al. Updates in diagnosis, management, and treatment of neuroblastoma. Radiographics 2018; 38 : 566-580.

4. Siegel MJ, Jaju A. MR imaging of neuroblastic masses. Magn Reson Imaging Clin N Am 2008; 16: 499-513.

5. Cohn SL, Pearson AD, London WB, et al. INRG Task Force. The International Neuroblastoma Risk Group (INRG) classification system: An INRG Task Force report. J Clin Oncol 2009; 27: 289-297.

6. Brodeur GM, Pritchard J, Berthold F, et al. Revisions of the international criteria for neuroblastoma diagnosis, staging, and response to treatment. J Clin Oncol 1993; 11: 1466-1477.

7. Monclair T, Brodeur GM, Ambros PF, et al. The International Neuroblastoma Risk Group (INRG) staging system: an INRG Task Force report. J Clin Oncol 2009; 27: 298-303.

8. Petjak M, Tiel-van Buul MM, Staalman CR, et al. Diagnostic imaging in abdominal neuroblastoma: is there a complementary role of MIBG-scintigraphy and ultrasonography? Eur J Pediatr 1997; 156 610-615.

9. Choi YJ, Hwang HS, Kim HJ, et al. (18)F-FDG PET as a single imaging modality in pediatric neuroblastoma: comparison with abdomen CT and bone scintigraphy. Ann Nucl Med 2014; 28: 304-313.

10. Owens C, Li BK, Thomas KE, Irwin MS. Surveillance imaging and radiation exposure in the detection of relapsed neuroblastoma. Pediatr Blood Cancer. 2016;63(10):1786-93. doi: 10.1002/pbc.26099.

11. Brennan P, Silman A. Statistical methods for assessing observer variability in clinical measures. BMJ 1992; 304:1491-4. doi: https:// doi.org/10.1136/bmj.304.6840.1491.

12. Altman DG. Practical statistics for medical research. London: Chapman and Hall; 1991.

13. Ng Y, Kingston J. The role of radiology in the staging of neuroblastoma. Clin Radiol 1993;47:226-35. doi: https://doi.org/10.1016/ S0009-9260(05)81128-6.
14. Kornreich L, Horev G, Kaplinsky C, Ziv N, Grünebaum M. Neuroblastoma: evaluation with contrast enhanced MR imaging. Pediatr Radiol 1991;21:566-9. doi: https://doi.org/10.1007/BF02012599.

15. Brisse HJ, McCarville MB, Granata C, et al. Guidelines for imaging and staging of neuroblastic tumors: consensus report from the International Neuroblastoma Risk Group Project. Radiology. 2011;261(1):243-57. doi: 10.1148/radiol.11101352.

16. Callahan MJ, MacDougall RD, Bixby SD, Voss SD, Robertson RL, Cravero JP. Ionizing radiation from computed tomography versus anesthesia for magnetic resonance imaging in infants and children: patient safety considerations. Pediatr Radiol. 2018;48(1):21-30. doi: 10.1007/s00247-017-4023-6.

17. Sofka CM, Semelka RC, Kelekis NL, et al. Magnetic resonance imaging of neuroblastomausing current techniques. Magn Reson Imaging 1999; 17 ( 2 ): 193-8. doi: https://doi.org/10.1016/S0730725X(98)00102-7.

18. Kushner BH. Neuroblastoma: a disease requiring a multitude of imaging studies. J Nucl Med. 2004;45(7):1172-88. PMID: 15235064

19. Siegel MJ, Ishwaran H, Fletcher BD, et al. Staging of neuroblastoma at imaging: report of the radiology diagnostic oncology group. Radiology. 2002;223(1):168-75. doi: 10.1148/radiol.2231010841.

20. Li AE, Li BT, Ng BHK, McCormack S, et al. Diagnostic Accuracy of Imaging Modalities in the Evaluation of Vascular Invasion in Pancreatic Adenocarcinoma: A Meta-Analysis. World J Oncol. 2013;4(2):74-82. doi: 10.4021/wjon657w.

21. Sauvat F, Brisse H, Magdeleinat P, et al. The transmanubrial approach: a new operative approach to cervicothoracic neuroblastoma in children. Surgery 2006;139(1): 109-14. doi: 10.1016/j. surg.2005.07.029.

22. Hiorns MP, Owens CM. Radiology of neuroblastoma in children. Eur Radiol 2001; 11(10): 2071-81. doi: 10.1007/s003300100931.

23. Sharp SE, Trout AT, Weiss BD, Gelfand MJ. MIBG in Neuroblastoma Diagnostic Imaging and Therapy. Radiographics. 2016;36(1):258-78. doi: 10.1148/rg.2016150099.

24. Vanel D. MRI of bone metastases: the choice of the sequence. Cancer Imaging. 2004;4(1):30-5. doi: 10.1102/1470-7330.2003.0029.

25. Fernandez-Pineda I, Sandoval JA, Davidoff AM. Hepatic metastatic disease in pediatric and adolescent solid tumors. World J Hepatol. 2015;7(14):1807-17. doi: 10.4254/wjh.v7.i14.1807. 